\title{
Recent Advances of $\mathrm{SnO}_{2}$-Based Sensors for Detecting Volatile Organic Compounds
}

\author{
Baoliang $\mathrm{Li}^{1}$, Qu Zhou ${ }^{1 *}$, Shudi Peng ${ }^{2}$ and Yiming Liao ${ }^{1}$ \\ ${ }^{1}$ College of Engineering and Technology, Southwest University, Chongqing, China, ${ }^{2}$ Chongqing Electric Power Research \\ Institute, State Grid Chongqing Electric Power Company, Chongqing, China
}

$\mathrm{SnO}_{2}$ based sensors has received extensive attention in the field of toxic gas detection due to their excellent performances with high sensitivity, fast response, long-term stability. Volatile organic compounds (VOCs), originate from industrial production, fuel burning, detergent, adhesives, and painting, are poisonous gases with significant effects on air quality and human health. This mini-review focuses on significant improvement of $\mathrm{SnO}_{2}$ based sensors in VOCs detection in recent years. In this review, the sensing mechanism of $\mathrm{SnO}_{2}$-based sensors detecting VOCs are discussed. Furthermore, the improvement strategies of the $\mathrm{SnO}_{2}$ sensor from the perspective of nanomaterials are presented. Finally, this paper summarizes the sensing performances of these $\mathrm{SnO}_{2}$

OPEN ACCESS

Edited by:

Weiwei Wu,

Xidian University, China

Reviewed by:

Wei Luo,

Donghua University, China Mingzai Wu,

Anhui University, China

${ }^{*}$ Correspondence:

Qu Zhou

zhouqu@swu.edu.cn

Specialty section:

This article was submitted to Nanoscience,

a section of the journal

Frontiers in Chemistry

Received: 29 January 2020 Accepted: 30 March 2020

Published: 05 May 2020

Citation:

Li B, Zhou Q, Peng S and Liao Y (2020) Recent Advances of

$\mathrm{SnO}_{2}$-Based Sensors for Detecting Volatile Organic Compounds.

Front. Chem. 8:321.

doi: 10.3389/fchem.2020.00321 nanomaterial sensors in VOCs detection, and the future development prospect and challenges is proposed.

Keywords: $\mathrm{SnO}_{2}$ based sensor, gas detection, vOCs, nanomaterials, improvement strategies

\section{INTRODUCTION}

Volatile Organic Compounds (VOCs) are the most crucial cause of indoor air pollution and harm to human health, including a variety of toxic compounds and carcinogens (Shrubsole et al., 2019). For example, organic waste gases such as formaldehyde and polycyclic aromatic hydrocarbons have strong carcinogenicity, when the human body is in this environment for a long time, the possibility of carcinogenesis will greatly increase. There are also some organic waste gas shows a strong toxic effect, the human body in the excessive inhalation, will lead to coma or even death (Li G. et al., 2019). In addition, VOCs exhaust gas may also cause environmental problems such as acid rain, ozone layer damage, and atmospheric warming (Meng et al., 2018). Therefore, it is very essential to analyze the composition and concentration of VOCs in the air. Current methods for detecting VOCs include Gas Chromatography (GC), Gas Chromatography-mass spectrometry (GC-ms) and gas sensor detection (Vesely et al., 2003; Teixeira et al., 2004). GC determination of a single sample requires reference to known standards, and GC-ms requires a high time cost and complicated process. More importantly, both methods are offline and cannot detect the content and change of VOCs in real-time. In recent years, gas sensors has been widely noticed because of its fast detection speed, small volume, simple measurement and on-line monitoring.

Carbon materials and metal oxide semiconductor materials like $\mathrm{SnO}_{2}, \mathrm{ZnO}, \mathrm{WO}_{3}$, and $\mathrm{In}_{2} \mathrm{O}_{3}$ have received scientific and technological importance and are widely used to detect VOCs gases (Luo et al., 2016; Lin et al., 2019; Zhao et al., 2019b). $\mathrm{SnO}_{2}$ gas sensor has been extensively studied for its applications in air quality detection, flammable and explosive gas detection, and environmental monitoring (Zhang Q. Y. et al., 2018; Zhou et al., 2018c). Nanomaterials have 
become the focus of the best sensing materials in recent years. Nanomaterials have many natural advantages such as large specific surface area, small size, and lightweight (Lu et al., 2018a; Zhou et al., 2018a). At present, there are many kinds of structures such as nanowires, nanofilaments, nanowires hollow spheres, nanofilaments flowers, and nanotubes (Mirzaei et al., 2016; Zhang Q. Y. et al., 2017). Different nanostructures and morphologies have different effects on the properties of materials. In order to change the nanostructure of a single material, there are other ways to improve the gas sensitivity of the sensor. This mini-review summaries the gas-sensing performances of $\mathrm{SnO}_{2}$ based sensor, which were influenced by the microstructure, doping, oxide composite and noble metal modification, toward toluene $\left(\mathrm{C}_{6} \mathrm{H}_{5} \mathrm{CH}_{3}\right)$, formaldehyde ( $\mathrm{HCHO})$, and acetone $\left(\mathrm{C}_{3} \mathrm{H}_{6} \mathrm{O}\right)$.

\section{SENSING MECHANISM OF $\mathrm{SNO}_{2}$ GAS SENSOR}

$\mathrm{SnO}_{2}$ sensor is a surface-controlled gas sensor. The gassensing reaction can only cause changes in parameters such as surface conductivity of the semiconductor (Ducere et al., 2012; Korotcenkov and Cho, 2017). When exposed to air, oxygen molecules would be adsorbed on the surface of the $\mathrm{SnO}_{2}$ nanostructures and capture electrons from the conduction band of $\mathrm{SnO}_{2}$ to generate chemisorbed oxygen species $\left[\mathrm{O}_{2}^{-}, \mathrm{O}^{-}\right.$, and $\mathrm{O}^{2-}$, depending on temperatures; (Shahabuddin et al., 2017; Zhou et al., 2019)]. The chemical adsorption process can be explained by the following reactions:

$$
\begin{array}{r}
O_{2}(\text { gas }) \leftrightarrow O_{2}(\text { ads }) \\
O_{2}(a d s)+e^{-} \leftrightarrow O_{2}{ }^{-}(\text {ads })\left(T<150^{\circ} \mathrm{C}\right) \\
\mathrm{O}_{2}{ }^{-}(\text {ads })+e^{-} \leftrightarrow 2 \mathrm{O}^{-}(\text {ads })\left(150^{\circ} \mathrm{C}<\mathrm{T}<400^{\circ} \mathrm{C}\right) \\
\mathrm{O}^{-}(\text {ads })+e^{-} \leftrightarrow O^{2-}(\text { ads })\left(T>400^{\circ} \mathrm{C}\right)
\end{array}
$$

When $\mathrm{SnO}_{2}$ sensor contacts with the measured gas, its resistance will change according to the oxidation or reduction characteristics of the gas. Toluene, formaldehyde and acetone tested in this paper are reductive gases. When $\mathrm{SnO}_{2}$ material surface comes into contact with a reducing gas, the reducing gas will react with oxygen anions to produce carbon dioxide and water, and the resulting electrons will return to the conduction band of the semiconductor. Therefore, this process will increase the carrier concentration on the surface of $\mathrm{SnO}_{2}$ material, resulting in a decrease in the resistance value. When finally restored to the air environment, the sensor returns to its original state (Lu et al., 2018b; Al-Hashem et al., 2019; Mahajan and Jagtap, 2019). The sensing mechanism of the $\mathrm{SnO}_{2}$ sensor reacting with these gases can be represented by the following path, where $\mathrm{O}^{-}$is taken as an example (Lian et al., 2017; Zhu et al., 2019):

$$
\begin{array}{r}
\mathrm{C}_{6} \mathrm{H}_{5} \mathrm{CH}_{3}+18 \mathrm{O}^{-} \rightarrow 7 \mathrm{CO}_{2}+4 \mathrm{H}_{2} \mathrm{O}+18 e^{-} \\
\mathrm{HCHO}+2 \mathrm{O}^{-} \rightarrow \mathrm{CO}_{2}+\mathrm{H}_{2} \mathrm{O}+2 e^{-} \\
\mathrm{C}_{3} \mathrm{H}_{6} \mathrm{O}+8 \mathrm{O}^{-} \rightarrow 3 \mathrm{CO}_{2}+3 \mathrm{H}_{2} \mathrm{O}+8 e^{-}
\end{array}
$$

\section{OPTIMIZATION OF $\mathrm{SNO}_{2}$ GAS-SENSING MATERIALS}

With the development of semiconductor gas-sensing materials, it has been the focus of research to enhance their gas-sensing properties for gas detection. The most common preparation methods of $\mathrm{SnO}_{2}$ sensing materials include electrostatic spinning and hydrothermal methods, as shown in Figures 1A,B. Different preparation methods will change the structure and morphology of $\mathrm{SnO}_{2}$ sensing materials and further enhance the gas sensitivity (Long et al., 2018; Zhang Y. J. et al., 2018; Zhou et al., 2018b). This section mainly reflects the changes in the gas-sensing properties of $\mathrm{SnO}_{2}$ nanomaterials from the aspects of structure and morphology design, ion doping, oxide composite and noble metal modification (Chen et al., 2013; Das and Jayaraman, 2014).

Different nanostructures and morphologies cause various effects on the properties of materials. In this respect, various morphologies from $0-\mathrm{D}$ to $3-\mathrm{D}$ with unique physical and chemical properties have been successfully synthesized. High dispersivity, ultra-small diameter $0-\mathrm{D} \quad \mathrm{SnO}_{2}$ nanoparticles (Figure 1C) have highly effective surface areas and sufficient oxygen vacancies, which can improve the performance of nanoparticle based sensors (Matussin et al., 2020). 1-D $\mathrm{SnO}_{2}$ structure, such as nanofibers (Figure 1D), has excellent sensitivity and stability due to its large specific surface area, high porosity and good permeability (Li H. et al., 2019). Compared with low dimensional structure, 2-D structure possesses larger special surface area. In comparison to the 3-D structure, freestanding 2-D structures such as $\mathrm{SnO}_{2}$ nanosheets (Figure 1E) can provide better optimization including the modulation of the materials activity, surface polarization, and rich oxygen vacancies (Zhu et al., 2015). 3-D structures, such as microspheres, microflowers, and mesoporous structures, are assembled by diverse lower dimension fundamental blocks. Microstructured analyses suggest that the favorable gas sensitivity of $\mathrm{SnO}_{2}$ tapered layered nanostructures (Figure 1F) are mainly ascribed to the formation of more active surface defects and mismatches ( $\mathrm{Li}$ et al., 2017).

Ion doping can change the cell parameters of the material, the number of suspensions on the surface of the material and the richness of defects, thereby enhance the gas sensitivity of the sensor (Korotcenkov and Cho, 2014). The Y-doped $\mathrm{SnO}_{2}$ threedimensional flower-like nanostructure prepared by one-step hydrothermal method has a large number of rough nanoflakes, which increases the specific surface area and is more conducive to the adsorption and desorption of oxygen and formaldehyde gas. It is a highly sensitive formaldehyde detection material (Zhu et al., 2019). The doping of $\mathrm{Ce}$ ions into the $\mathrm{SnO}_{2}$ lattice results in the smaller size of nanoparticles and the formation of a porous structure. Therefore, Ce ions can provide more active sites for the adsorption and reaction of acetone (Lian et al., 2017).

The combination of two metal oxides can improve the gas sensitivity of semiconductor materials. The dispersion of functional components is the key factor to realize good gas sensitivities (Wei et al., 2020). Moreover, the heterostructure formed by $\mathrm{SnO}_{2}$ and another metal oxide can promote the transfer of carriers between materials and change the 


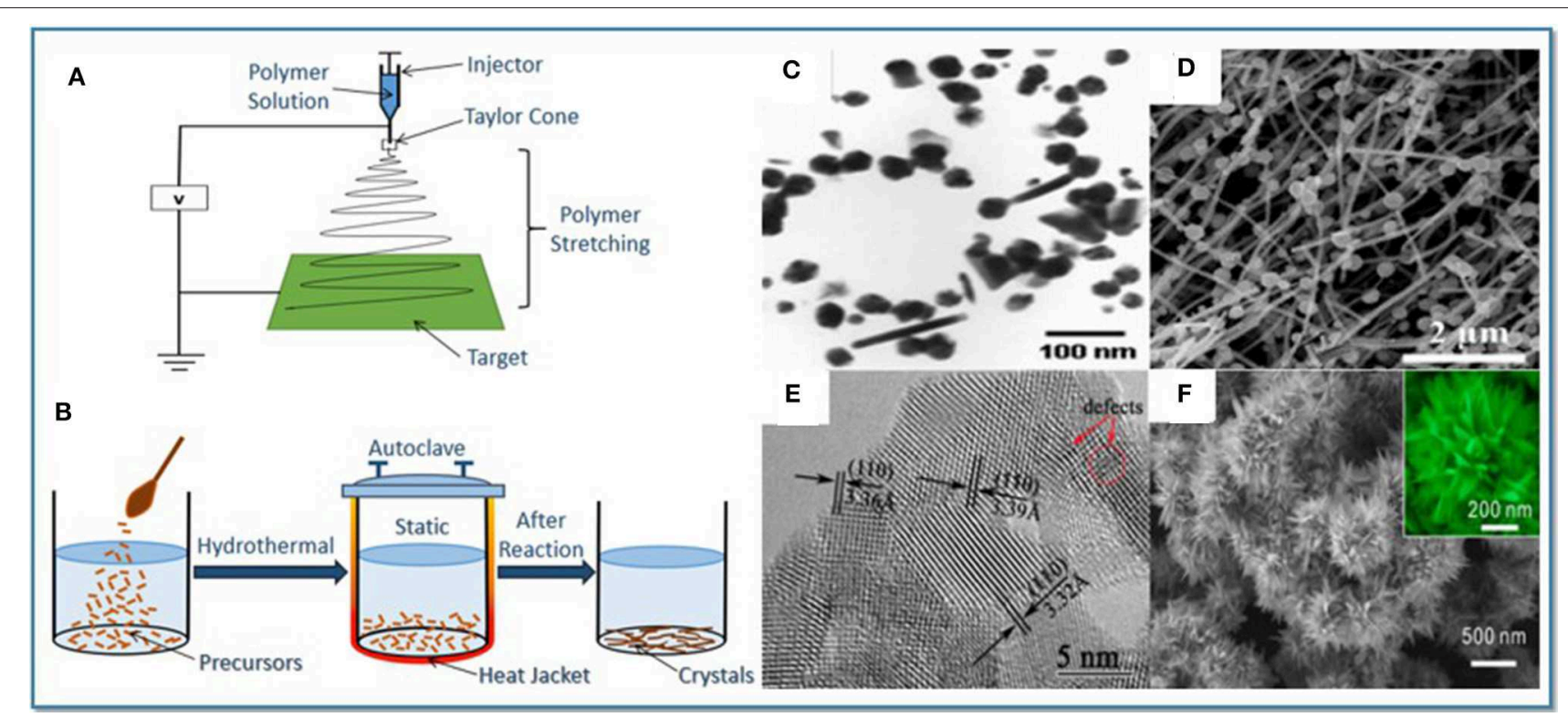

FIGURE 1 | (A) A schematic of electrospinning method. (B) A schematic of hydrothermal method. (C) $\mathrm{SnO}_{2}$ nanoparticles. Reprinted with permission from Matussin et al. (2020). (D) $\mathrm{SnO}_{2} / \mathrm{ZnO}$ nanofibers. Reprinted with permission from Li H. et al. (2019). (E) $\mathrm{SnO}_{2}$ nanosheets. Reprinted with permission from Zhu et al. (2015). (F) $\mathrm{SnO}_{2}$ tapered layered nanostructures. Reprinted with permission from Li et al. (2017).

conductivity and energy band structure of composite materials (Gusain et al., 2019; Wei et al., 2019). In a recent research, a facile solvent EIOC has been demonstrated for the synthesis of novel hierarchical branched mesoporous $\mathrm{TiO}_{2}-\mathrm{SnO}_{2}$ semiconducting heterojunctions. The uniform distribution of $\mathrm{SnO}_{2}$ NCs in the pore walls of $\mathrm{TiO}_{2}$ forms numerous $\mathrm{n}$-n heterojunctions which are extremely useful for surface catalytic reaction. Owing to the rational combination of a hierarchical mesoporous structure, a high crystallinity, and well-defined $n-n$ heterojunctions, the SHMT-based gas sensor shows an excellent sensing performance with a fast response and recovery dynamics, ultralow limit of detection and a superior selectivity (Zhao et al., 2019a). The cactus-like $\mathrm{WO}_{3}-\mathrm{SnO}_{2}$ nanocomposite was prepared by one-step hydrothermal method by attaching many tiny $\mathrm{SnO}_{2}$ nanospheres to large $\mathrm{WO}_{3}$ nanospheres, which provided many active sites for the acetone molecule and provided heterojunctions between $\mathrm{WO}_{3}$ and $\mathrm{SnO}_{2}$. The synergistic effect between them improves the sensing performance of the composite nanomaterial to acetone gas (Zhu et al., 2018).

Precious metal modification usually uses $\mathrm{Au}, \mathrm{Ag}, \mathrm{Pt}$, and $\mathrm{Pd}$ or their oxides to improve the sensitivity and response speed of gas sensing materials and reduce the working temperature. $\mathrm{Ag}$ modified $\mathrm{SnO}_{2}$ nanoparticles prepared by hydrothermal in situ reduction improved the sensor's ability to detect formaldehyde. This is due to the charge transfer between $\mathrm{Ag}$ and $\mathrm{SnO}_{2}$, which increases the absorption band on the composite by $20 \mathrm{~nm}$, thus improving the gas sensitivity (Liu et al., 2019). When the acetone is detected by $\mathrm{Ag} / \mathrm{SnO}_{2}$ porous tubular nanostructures prepared by electrospinning, the sensor resistance changed rapidly and significantly. On the one hand, the $\mathrm{p}-\mathrm{n}$ hybrid interface of $\mathrm{p}$ type $\mathrm{Ag}_{2} \mathrm{O}$ and $\mathrm{n}$-type $\mathrm{SnO}_{2}$ causes the energy band of the depletion layer to bend, increasing the initial resistance. On the other hand, the hollow nanostructure promotes the adsorption and electron transfer of acetone, which makes the resistance change rapidly (Xu et al., 2017). The bimetal PdAu modified $\mathrm{SnO}_{2}$ nanosheet showed excellent selectivity and responsiveness to low concentrations of acetone, which is due to the chemical sensitization of $\mathrm{Au}$, electronic sensitization of Pd and synergism of PdAu bimetal nanosheet (Li G. et al., 2019).

\section{SENSING PERFORMANCE OF VOCs BASED ON $\mathrm{SNO}_{2}$ NANOMATERIALS}

For VOCs, this review mainly introduces toluene, formaldehyde and acetone. This section summarizes the gas-sensitive characteristics of $\mathrm{SnO}_{2}$-based nanomaterials for the above gases, as shown in Table 1. In the detection of common VOCs, the lower detection limit, response value and detection temperature of $\mathrm{SnO}_{2}$ based nanomaterials are different.

Toluene, a colorless volatile liquid, is one of the most widely used aromatic hydrocarbons and is considered as a biomarker of cancer. Occupational Safety and Health Administration (OSHA) stipulates that the permissible exposure limit for toluene is 100 ppm for $8 \mathrm{~h}$ (Sui et al., 2017). The Pd-doped $\mathrm{SnO}_{2}$ hollow spheres prepared by hydrothermal method measured a response value of 52.9 for toluene at $20 \mathrm{ppm}$ and a lower temperature of $230^{\circ} \mathrm{C}$ (Zhang K. et al., 2017). The Pd-loaded $\mathrm{SnO}_{2}$ cubic nanocages are also an ideal choice for toluene detection, with a minimum detection concentration of $100 \mathrm{ppb}$, a response to $20 \mathrm{ppm}$ of toluene of 41.4 , and an optimal reaction temperature of $250^{\circ} \mathrm{C}$ (Qiao et al., 2017). Formaldehyde is a colorless and pungent gas. 
TABLE 1 | Comparison of $\mathrm{SnO}_{2}$ based nanomaterials for VOCs detection.

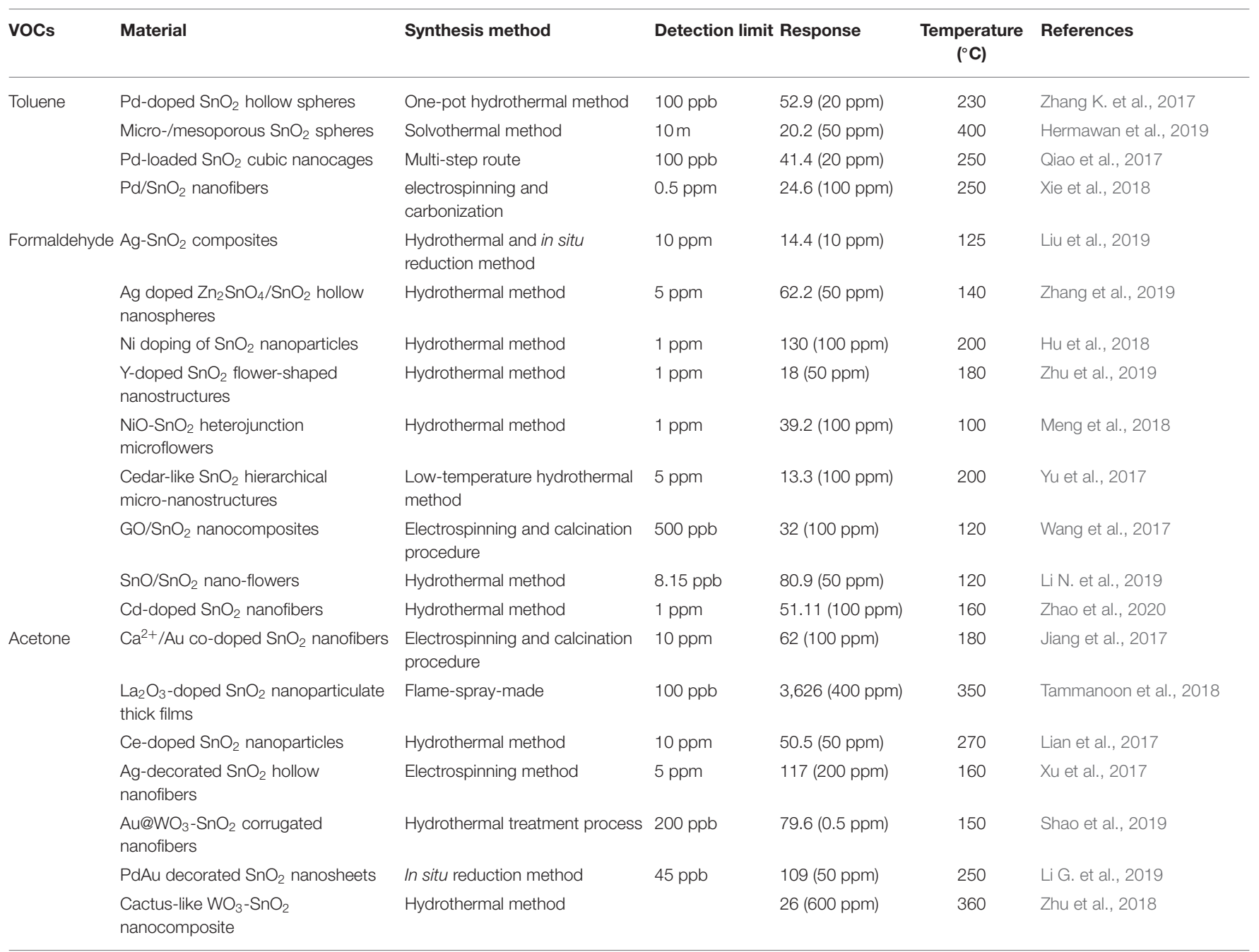

Due to the toxicity of formaldehyde, OSHA has established the Threshold Limit Value (TLV) as a concentration of $0.75 \mathrm{ppm}$ for $8 \mathrm{~h}$. The $\mathrm{SnO} / \mathrm{SnO}_{2}$ nano-flowers prepared by hydrothermal method have a minimum detection concentration of 8.15 for formaldehyde, an optimal response temperature of $120^{\circ} \mathrm{C}$, and a response value of 80.9 at $50 \mathrm{ppm}$. It is an ideal material for formaldehyde detection (Li N. et al., 2019). The hydrothermal $\mathrm{Ni}$ doping of $\mathrm{SnO}_{2}$ nanoparticles also had a good response value of $130-100 \mathrm{ppm}$ of formaldehyde at $200^{\circ} \mathrm{C}$ (Hu et al., 2018). In addition, the $\mathrm{Ag}$-doped $\mathrm{Zn}_{2} \mathrm{SnO}_{4} / \mathrm{SnO}_{2}$ hollow nanospheres responded to $50 \mathrm{ppm}$ of formaldehyde with a value of 62.2 and a lower detection temperature of $140^{\circ} \mathrm{C}$ (Zhang et al., 2019). Acetone is a colorless and irritant liquid. Long term exposure to acetone can stimulate human sensory organs and lead to inflammation. Therefore, the quantitative detection of acetone is of great significance (Cheng et al., 2015; Lian et al., 2017). $\mathrm{PdAu}$ decorated $\mathrm{SnO}_{2}$ nanosheets sensor was able to detect acetone at $45 \mathrm{ppb}$ and to respond to acetone at $50 \mathrm{ppm}$ to 109 (Li G. et al., 2019). The detection limit of $\mathrm{Au} @ \mathrm{WO}_{3}-\mathrm{SnO}_{2}$ corrugated nanofibers prepared by hydrothermal treatment was
$200 \mathrm{ppb}$ acetone, and the best response to $0.5 \mathrm{ppm}$ acetone at $150^{\circ} \mathrm{C}$ was 79.6. The Au@ $\mathrm{WO}_{3}-\mathrm{SnO}_{2}$ corrugated nanofibers is an ideal low concentration acetone gas sensor with low detection limit and high response (Shao et al., 2019). $\mathrm{La}_{2} \mathrm{O}_{3}$-doped $\mathrm{SnO}_{2}$ nanoparticle thick films has an amazing response value of 3,626 $-400 \mathrm{ppm}$ at $350^{\circ} \mathrm{C}$, which is suitable for the detection of high concentration acetone (Tammanoon et al., 2018).

\section{CONCLUSION AND PERSPECTIVE}

This review discusses the performance improvements of $\mathrm{SnO}_{2}$ based nanomaterials and the comparison of gas sensitivity in VOCs in recent years. $\mathrm{SnO}_{2}$-based nanostructures provide a larger specific surface area and more active sites, which is conducive to VOCs adsorption. Ion doping can reduce the size of nanomaterials and make the surface of the material rougher, thereby increasing the specific surface area. Metal oxide composite can not only achieve functional dispersion, but also form heterojunctions to promote the movement of charge 
carriers. Precious metals have excellent catalytic activity for $\mathrm{SnO}_{2}$ nanomaterials. These optimization methods make $\mathrm{SnO}_{2}$-based gas sensors operate at lower temperatures, higher sensitivity, and better stability. Despite great progress has been made in the application of $\mathrm{SnO}_{2}$ nanomaterials, there is still much room for further development. First of all, cross sensitivity is a huge challenge for the preparation of high-performance sensors. In the future, $\mathrm{SnO}_{2}$ gas sensor will be able to detect a single gas in the mixture. Secondly, most of the $\mathrm{SnO}_{2}$ sensors currently used work at high temperature, which limits their wide application in detecting VOCs at room temperature. In addition, long-term stability is also one of the research hotspots of $\mathrm{SnO}_{2}$ sensors in the future. Due to the influence of external environment and other factors, the stability of the sensor can not be guaranteed. Therefore, it is of great significance to develop more stable gas sensors. It has become a research hotspot to optimize the existing gas sensing materials by chemical modification and develop new gas sensing materials such as composite and hybrid semiconductor materials and polymer gas sensing materials. In addition, new sensors, such as optical waveguide gas sensor,

\section{REFERENCES}

Al-Hashem, M., Akbar, S., and Morris, P. (2019). Role of oxygen vacancies in nanostructured metal-oxide gas sensors: a review. Sensor. Actuat. B Chem. 301:126845. doi: 10.1016/j.snb.2019.126845

Chen, W. G., Zhou, Q., Gao, T. Y., Su, X. P., and Wan, F. (2013). Pd-doped $\mathrm{SnO}_{2}-$ based sensor detecting characteristic fault hydrocarbon gases in transformer oil. J. Nanomater. 2013:127345. doi: 10.1155/2013/127345

Cheng, L., Ma, S. Y., Wang, T. T., and Luo, J. (2015). Synthesis and enhanced acetone sensing properties of $3 \mathrm{D}$ porous flower-like $\mathrm{SnO}_{2}$ nanostructures. Mater. Lett. 143, 84-87. doi: 10.1016/j.matlet.2014.12.062

Das, S., and Jayaraman, V. (2014). $\mathrm{SnO}_{2}$ : a comprehensive review on structures and gas sensors. Prog. Mater. Sci. 66, 112-255. doi: 10.1016/j.pmatsci.2014.06.003

Ducere, J. M., Hemeryck, A., Esteve, A., Rouhani, M. D., Landa, G., Menini, P., et al. (2012). A computational chemist approach to gas sensors: modeling the response of $\mathrm{SnO}_{2}$ to $\mathrm{CO}, \mathrm{O}_{2}$, and $\mathrm{H}_{2} \mathrm{O}$ gases. J. Comput. Chem. 33, 247-258. doi: $10.1002 /$ jcc. 21959

Gusain, R., Gupta, K., Joshi, P., and Khatri, O. P. (2019). Adsorptive removal and photocatalytic degradation of organic pollutants using metal oxides and their composites: a comprehensive review. Adv. Colloid. Interface. 272:102009. doi: 10.1016/j.cis.2019.102009

Hermawan, A., Asakura, Y., Inada, M., and Yin, S. (2019). One-step synthesis of micro-/mesoporous $\mathrm{SnO}_{2}$ spheres by solvothermal method for toluene gas sensor. Ceram. Int. 45, 15435-15444. doi: 10.1016/j.ceramint.2019.05.043

Hu, J., Wang, T., Wang, Y., Huang, D., He, G., Han, Y., et al. (2018). Enhanced formaldehyde detection based on $\mathrm{Ni}$ doping of $\mathrm{SnO}_{2}$ nanoparticles by one-step synthesis. Sensor. Actuat. B Chem. 263, 120-128. doi: 10.1016/j.snb.2018.02.035

Jiang, Z., Yin, M., and Wang, C. (2017). Facile synthesis of $\mathrm{Ca}^{2+} / \mathrm{Au}$ co-doped $\mathrm{SnO}_{2}$ nanofibers and their application in acetone sensor. Mater. Lett. 194, 209-212. doi: 10.1016/j.matlet.2017.02.031

Korotcenkov, G., and Cho, B. K. (2014). Bulk doping influence on the response of conductometric $\mathrm{SnO}_{2}$ gas sensors: understanding through cathodoluminescence study. Sensor. Actuat. B Chem. 196, 80-98. doi: 10.1016/j.snb.2014.01.108

Korotcenkov, G., and Cho, B. K. (2017). Metal oxide composites in conductometric gas sensors: achievements and challenges. Sensor. Actuat. B Chem. 244, 182-210. doi: 10.1016/j.snb.2016.12.117

Li, G., Cheng, Z., Xiang, Q., Yan, L., Wang, X., and Xu, J. (2019). Bimetal PdAu decorated $\mathrm{SnO}_{2}$ nanosheets based gas sensor with temperature-dependent dual selectivity for detecting formaldehyde and acetone. Sensor. Actuat. B Chem. 283, 590-601. doi: 10.1016/j.snb.2018.09.117 quartz resonant gas sensor and microbial gas sensor, developed with advanced processing technology and microstructure, can make the sensor more stable, and versatility. Finally, we hope our work will be helpful for the further exploration of metal oxide nanomaterials in the detection of VOCs.

\section{AUTHOR CONTRIBUTIONS}

All authors listed have made a substantial, direct and intellectual contribution to the work, and approved it for publication.

\section{FUNDING}

This work has been supported in part by the National Natural Science Foundation of China (No. 51507144), Fundamental Research Funds for the Central Universities (No. XDJK2019B021), the Chongqing Science and Technology Commission (CSTC) (No. cstc2016jcyjA0400), and the project of China Scholarship Council (CSC).
Li, H., Chu, S. S., Ma, Q., Li, H., Che, Q. D., Wang, J. P., et al. (2019). Multilevel effective heterojunctions based on $\mathrm{SnO}_{2} / \mathrm{ZnO}$ 1D fibrous hierarchical structure with unique interface electronic effects. Acs. Appl. Mater. Inter. 11, 31551-31561. doi: 10.1021/acsami.9b10410

Li, N., Fan, Y., Shi, Y., Xiang, Q., Wang, X., and Xu, J. (2019). A low temperature formaldehyde gas sensor based on hierarchical $\mathrm{SnO} / \mathrm{SnO}_{2}$ nano-flowers assembled from ultrathin nanosheets: Synthesis, sensing performance and mechanism. Sensor. Actuat. B Chem. 294, 106-115. doi: 10.1016/j.snb.2019.04.061

Li, Y. X., Guo, Z., Su, Y., Jin, X. B., Tang, X. H., Huang, J. R., et al. (2017). Hierarchical morphology-dependent gas-sensing performances of three-dimensional $\mathrm{SnO}_{2}$ nanostructures. Acs. Sens. 2, 102-110. doi: 10.1021/acssensors.6b00597

Lian, X., Li, Y., Tong, X., Zou, Y., Liu, X., An, D., et al. (2017). Synthesis of Cedoped $\mathrm{SnO}_{2}$ nanoparticles and their acetone gas sensing properties. Appl. Surf. Sci. 407, 447-455. doi: 10.1016/j.apsusc.2017.02.228

Lin, T., Lv, X., Hu, Z., Xu, A., and Feng, C. (2019). Semiconductor metal oxides as chemoresistive sensors for detecting volatile organic compounds. Sensors Basel. 19:233. doi: 10.3390/s19020233

Liu, D., Pan, J., Tang, J., Liu, W., Bai, S., and Luo, R. (2019). Ag decorated $\mathrm{SnO}_{2}$ nanoparticles to enhance formaldehyde sensing properties. J. Phys. Chem. Solids. 124, 36-43. doi: 10.1016/j.jpcs.2018.08.028

Long, H., Zeng, W., Wang, H., Qian, M., Liang, Y., and Wang, Z. (2018). Selfassembled biomolecular 1D nanostructures for aqueous sodium-ion battery. Adv. Sci. 5:1700634. doi: 10.1002/advs.201700634

Lu, Z. R., Zhou, Q., Wang, C. S., Wei, Z. J., Xu, L. N., and Gui, Y. G. (2018a). Electrospun $\mathrm{ZnO}-\mathrm{SnO}_{2}$ composite nanofifibers and enhanced sensing properties to $\mathrm{SF}_{6}$ decomposition byproduct $\mathrm{H}_{2} \mathrm{~S}$. Front. Chem. 6:540. doi: $10.3389 /$ fchem. 2018.00540

Lu, Z. R., Zhou, Q., Xu, L. N., Gui, Y. G., Zhao, Z. Y., Tang, C., et al. (2018b). Synthesis and characterization of highly sensitive hydrogen $\left(\mathrm{H}_{2}\right)$ sensing device based on $\mathrm{Ag}$ doped $\mathrm{SnO}_{2}$ nanospheres. Materials. 11:492. doi: 10.3390/ma11040492

Luo, W., Zhao, T., Li, Y. H., Wei, J., Xu, P. C., Li, X. X., et al. (2016). A micelle fusion-aggregation assembly approach to mesoporous carbon materials with rich active sites for ultra-sensitive ammonia. Sensing. J. Am. Chem. Soc. 138, 12586-12595. doi: 10.1021/jacs.6b 07355

Mahajan, S., and Jagtap, S. (2019). Metal-oxide semiconductors for carbon monoxide (CO) gas sensing: a review. Appl. Mater. Today. 18:100483. doi: 10.1016/j.apmt.2019.100483 
Matussin, S., Harunsani, M. H., Tan, A. L., and Khan, M. M. (2020). Plant-extractmediated $\mathrm{SnO}_{2}$ nanoparticles: synthesis and applications. Acs. Sustain. Chem. Eng. 8, 3040-3054. doi: 10.1021/acssuschemeng.9b06398

Meng, D., Liu, D., Wang, G., Shen, Y., San, X., Li, M., et al. (2018). Lowtemperature formaldehyde gas sensors based on $\mathrm{NiO}-\mathrm{SnO}_{2}$ heterojunction microflowers assembled by thin porous nanosheets. Sensor. Actuat. B Chem. 273, 418-428. doi: 10.1016/j.snb.2018.06.030

Mirzaei, A., Leonardi, S. G., and Neri, G. (2016). Detection of hazardous volatile organic compounds (VOCs) by metal oxide nanostructures-based gas sensors: a review. Ceram. Int. 42, 15119-15141. doi: 10.1016/j.ceramint.2016.06.145

Qiao, L., Bing, Y., Wang, Y., Yu, S., Liang, Z., and Zeng, Y. (2017). Enhanced toluene sensing performances of $\mathrm{Pd}$ - loaded $\mathrm{SnO}_{2}$ cubic nanocages with porous nanoparticle-assembled shells. Sensor. Actuat. B Chem. 241, 1121-1129. doi: 10.1016/j.snb.2016.10.024

Shahabuddin, M., Umar, A., Tomar, M., and Gupta, V. (2017). Custom designed metal anchored $\mathrm{SnO}_{2}$ sensor for $\mathrm{H}_{2}$ detection. Int. J. Hydrogen Energ. 42, 4597-4609. doi: 10.1016/j.ijhydene.2016.12.054

Shao, S., Chen, X., Chen, Y., Lai, M., and Che, L. (2019). Ultrasensitive and highly selective detection of acetone based on $\mathrm{Au} @ \mathrm{WO}_{3}-\mathrm{SnO}_{2}$ corrugated nanofibers. Appl. Surf. Sci. 473, 902-911. doi: 10.1016/j.apsusc.2018.12.208

Shrubsole, C., Dimitroulopoulou, S., Foxall, K., Gadeberg, B., and Doutsi, A. (2019). IAQ guidelines for selected volatile organic compounds (VOCs) in the UK. Build. Environ. 165:106382. doi: 10.1016/j.buildenv.2019.106382

Sui, L. L., Zhang, X. F., Cheng, X. L., Wang, P., Xu, Y. M., Gao, S., et al. (2017). Au-loaded hierarchical $\mathrm{MoO}_{3}$ hollow spheres with enhanced gassensing performance for the detection of BTX (benzene, toluene, and xylene) and the sensing mechanism. Acs. Appl. Mater. Inter. 9, 1661-1670. doi: 10.1021/acsami.6b11754

Tammanoon, N., Wisitsoraat, A., Phokharatkul, D., Tuantranont, A., Phanichphant, S., Yordsri, V., et al. (2018). Highly sensitive acetone sensors based on flame-spray-made $\mathrm{La}_{2} \mathrm{O}_{3}$-doped $\mathrm{SnO}_{2}$ nanoparticulate thick films. Sensor. Actuat. B Chem. 262, 245-262. doi: 10.1016/j.snb.2018.01.238

Teixeira, L. S., Leao, E. S., Dantas, A. F., Pinheiro, H. L., Costa, A. C., and de Andrade, J. B. (2004). Determination of formaldehyde in Brazilian alcohol fuels by flow-injection solid phase spectrophotometry. Talanta 64, 711-715. doi: $10.1016 /$ j.talanta.2004.03.047

Vesely, P., Lusk, L., Basarova, G., Seabrooks, J., and Ryder, D. (2003). Analysis of aldehydes in beer using solid-phase microextraction with on-fiber derivatization and gas chromatography/mass spectrometry. J. Agr. Food Chem. 51, 6941-6944. doi: 10.1021/jf034410t

Wang, D., Zhang, M., Chen, Z., Li, H., Chen, A., Wang, X., et al. (2017). Enhanced formaldehyde sensing properties of hollow $\mathrm{SnO}_{2}$ nanofibers by graphene oxide. Sensor. Actuat. B Chem. 250, 533-542. doi: 10.1016/j.snb.2017.04.164

Wei, Z. J., Zhou, Q., Wang, J. X., Lu, Z. R., Xu, L. N., and Zeng, W. (2019). Hydrothermal synthesis of $\mathrm{SnO}_{2}$ nanoneedle-anchored $\mathrm{NiO}$ microsphere and its gas sensing performances. Nanomaterials Basel. 9:1015. doi: $10.3390 /$ nano9071015

Wei, Z. J., Zhou, Q., and Zeng, W. (2020). Hierarchical $\mathrm{WO}_{3}-\mathrm{NiO}$ microflower for high sensitivity detection of $\mathrm{SF}_{6}$ decomposition byproduct $\mathrm{H}_{2} \mathrm{~S}$. Nanotechnology 31:215701. doi: 10.1088/1361-6528/ab73bd

Xie, N., Guo, L. L., Chen, F., Kou, X. Y., Wang, C., Ma, J., et al. (2018). Enhanced sensing properties of $\mathrm{SnO}_{2}$ nanofibers with a novel structure by carbonization. Sensor. Actuat. B Chem. 271, 44-53. doi: 10.1016/j.snb.2018.05.039

Xu, X., Chen, Y., Zhang, G., Ma, S., Lu, Y., Bian, H., et al. (2017). Highly sensitive VOCs-acetone sensor based on Ag-decorated $\mathrm{SnO}_{2}$ hollow nanofibers. J. Alloy. Compd. 703, 572-579. doi: 10.1016/j.jallcom.2017.01.348

Yu, H., Yang, T., Wang, Z., Li, Z., Xiao, B., Zhao, Q., et al. (2017). Facile synthesis cedar-like $\mathrm{SnO}_{2}$ hierarchical micro-nanostructures with improved formaldehyde gas sensing characteristics. J. Alloy. Compd. 724, 121-129. doi: 10.1016/j.jallcom.2017.07.017

Zhang, K., Yang, X., Wang, Y., Bing, Y., Qiao, L., Liang, Z., et al. (2017). Pd-loaded $\mathrm{SnO}_{2}$ ultrathin nanorod-assembled hollow microspheres with the significant improvement for toluene detection. Sensor. Actuat. B Chem. 243, 465-474. doi: 10.1016/j.snb.2016.11.153
Zhang, Q. Y., Zhou, Q., Lu, Z. R., Wei, Z. J., Xu, L. N., and Gui, Y. G. (2018). Recent advances of $\mathrm{SnO}_{2}$-based sensors for detecting fault characteristic gases extracted from power transformer oil. Front. Chem. 6:364. doi: 10.3389/Fchem.2018.00364

Zhang, Q. Y., Zhou, Q., Yin, X. T., Liu, H. C., Xu, L. N., Tan, W. M., et al. (2017). The effect of PMMA pore-forming on hydrogen sensing properties of porous $\mathrm{SnO}_{2}$ thick film sensor. Adv. Sci. 9, 1350-1355. doi: 10.1166/sam.2017.3111

Zhang, R., Ma, S. Y., Zhang, Q. X., Zhu, K. M., Tie, Y., Pei, S. T., et al. (2019). Highly sensitive formaldehyde gas sensors based on Ag doped $\mathrm{Zn}_{2} \mathrm{SnO}_{4} / \mathrm{SnO}_{2}$ hollow nanospheres. Mater. Lett. 254, 178-181. doi: 10.1016/j.matlet.2019.07.065

Zhang, Y. J., Zeng, W., and Li, Y. Q. (2018). The hydrothermal synthesis of $3 \mathrm{D}$ hierarchical porous $\mathrm{MoS}_{2}$ microspheres assembled by nanosheets with excellent gas sensing properties. J. Alloy. Compd. 749, 355-362. doi: 10.1016/j.jallcom.2018.03.307

Zhao, R., Zhang, X., Peng, S., Hong, P., Zou, T., Wang, Z., et al. (2020). Shaddock peels as bio-templates synthesis of Cd-doped $\mathrm{SnO}_{2}$ nanofibers: a high performance formaldehyde sensing material. J. Alloy. Compd. 813:152170. doi: 10.1016/j.jallcom.2019.152170

Zhao, T., Qiu, P. P., Fan, Y. C., Yang, J. P., Jiang, W., Wang, L. J., et al. (2019a). Hierarchical branched mesoporous $\mathrm{TiO}_{2}-\mathrm{SnO}_{2}$ nanocomposites with well-defined $n-n$ heterojunctions for highly efficient ethanol sensing. Adv. Sci. 6:1902008. doi: 10.1002/advs.201902008

Zhao, T., Ren, Y., Jia, G. Y., Zhao, Y. Y., Fan, Y. C., Yang, J. P., et al. (2019b). Facile synthesis of mesoporous $\mathrm{WO}_{3} @$ graphene aerogel nanocomposites for low-temperature acetone sensing. Chin. Chem. Lett. 30, 2032-2038. doi: 10.1016/j.cclet.2019.05.006

Zhou, Q., Chen, W. G., Xu, L. N., Kumar, R., Gui, Y. G., Zhao, Z. Y., et al. (2018a). Highly sensitive carbon monoxide (CO) gas sensors based on $\mathrm{Ni}$ and $\mathrm{Zn}$ doped $\mathrm{SnO}_{2}$ nanomaterials. Ceram. Int. 44, 4392-4399. doi: 10.1016/j.ceramint.2017.12.038

Zhou, Q., Umar, A., Sodki, E., Amine, A., Xu, L. N., Gui, Y. G., et al. (2018b). Fabrication and characterization of highly sensitive and selective sensors based on porous $\mathrm{NiO}$ nanodisks. Sensor. Actuat. B Chem. 259, 604-615. doi: 10.1016/j.snb.2017.12.050

Zhou, Q., Xu, L. N., Umar, A., Chen, W. G., and Kumar, R. (2018c). $\mathrm{Pt}$ nanoparticles decorated $\mathrm{SnO}_{2}$ nanoneedles for effificient CO gas sensing applications. Sensor. Actuat. B Chem. 256, 656-664. doi: 10.1016/j.snb.2017.09.206

Zhou, Q., Zeng, W., Chen, W. G., Xu, L. N., Kumar, R., and Umar, A. (2019). High sensitive and low-concentration sulfur dioxide $\left(\mathrm{SO}_{2}\right)$ gas sensor application of heterostructure NiO-ZnO nanodisks. Sensor. Actuat. B Chem. 298:126870. doi: 10.1016/j.snb.2019.126870

Zhu, K., Ma, S., Tie, Y., Zhang, Q., Wang, W., Pei, S., et al. (2019). Highly sensitive formaldehyde gas sensors based on Y-doped $\mathrm{SnO}_{2}$ hierarchical flower-shaped nanostructures. J. Alloy. Compd. 792, 938-944. doi: 10.1016/j.jallcom.2019.04.102

Zhu, L., Zeng, W., and Li, Y. (2018). A novel cactus-like $\mathrm{WO}_{3}-\mathrm{SnO}_{2}$ nanocomposite and its acetone gas sensing properties. Mater. Lett. 231, 5-7. doi: 10.1016/j.matlet.2018.08.007

Zhu, Y. Q., Guo, H. Z., Zhai, H. Z., and Cao, C. B. (2015). Microwaveassisted and gram-scale synthesis of ultrathin $\mathrm{SnO}_{2}$ nanosheets with enhanced lithium storage properties. Acs. Appl. Mater. Inter. 7, 2745-2753. doi: $10.1021 / \mathrm{am} 507826 \mathrm{~d}$

Conflict of Interest: The authors declare that the research was conducted in the absence of any commercial or financial relationships that could be construed as a potential conflict of interest.

Copyright (c) $2020 \mathrm{Li}$, Zhou, Peng and Liao. This is an open-access article distributed under the terms of the Creative Commons Attribution License (CC BY). The use, distribution or reproduction in other forums is permitted, provided the original author(s) and the copyright owner(s) are credited and that the original publication in this journal is cited, in accordance with accepted academic practice. No use, distribution or reproduction is permitted which does not comply with these terms. 